\title{
STUDY OF INFLUENCE OF BACTERIAL LYSATE ON CYTOKINE INDICATORS IN EXPERIMENTAL PERIODONTIS IN RATS
}

\author{
Mariia Ievtushenko \\ Department of Clinical Pathophysiology, Topographic Anatomy and Operative Surgery ${ }^{1}$ \\ Elena Kosheva \\ Department of Microbiology, Virology and Immunology \\ National University of Pharmacy \\ 53 Pushkinska str., Kharkiv, Ukraine, 61002 \\ Svitlana Kryzhna $\bowtie$ \\ Department of Clinical Pathophysiology, Topographic Anatomy and Operative Surgery ${ }^{1}$ \\ kryghna@gmail.com
}

${ }^{1}$ Kharkiv Medical Academy of Postgraduate Education

58 Amosova str., Kharkiv, Ukraine, 61176

$\bowtie$ Corresponding author

\begin{abstract}
The aim of the research: to optimize the treatment of patients with a disturbed cytokine profile by a bacterial lysate in an experimental model of periodontitis against the background of changes in the local and systemic immune response.

Materials and methods: prospective study has been conducted on experimental periodontitis in 42 rats for 90 days. The animals were treated by solution of «Respibron» and the reference drug «Imudon». The concentration of cytokines in the blood serum was determined by the enzyme immunoassay, circulating immune complexes - precipitation method is measured on a spectrophotometer, C-reactive protein - using a latex diagnosticum. All interventions and euthanasia of animals were carried out in compliance with the European principles.

Results: the obtained data from the study indicate a high degree a state of decompensation of experimental periodontitis. An immuno-inflammatory reaction preceding periodontitis is accompanied by the disturbances of the cytokine balance, local and systemic immune response. Applying of bacterial lysates led to the compensation of bacterial dysbiosis, restoration of the balance of the activity of pro- and anti-inflammatory cytokines, and a decrease the hyperactivity of immunological markers.

Conclusion: the studies carried out have shown that the use of bacterial lysate is a pathogenetically substantiated component of therapeutic tactics. The normalizing effect of the lysate on the parameters of the immune response and cytokine profile has been reliably shown. Considering the immuno-inflammatory reaction at the experimental periodontitis, accompanied by the cytokine imbalance, study the pharmacological correction by bacterial lysate should continue from the point of view of establishing the mechanisms of development, protection, and restoration of tissues.

1. It has been proved that by the end of the 90 -day period of observation of the course of experimental periodontitis, the power of natural compensatory mechanisms acquired a state of decompensation. It has manifested by increased pro-inflammatory cytokine IL-1 $\beta$ in 1.7 times, and TNF- $\alpha$ in 3 times, decreased anti-inflammatory cytokine IL-10 in 1.6 times; increased the concentration of CIC in the blood in 2 times, C-reactive protein in 4.4 times at the local level in the gum tissue homogenate of the control pathology group of animals.

2. The powerful corrective effect of bacterial lysates «Respibron» and «Imudon» on the indicators of the cytokine series on the model of chronic experimental periodontitis has been reliably established. The normalizing effect is due to the compensation of bacterial dysbiosis, restoration of the balance of the activity of pro- and anti-inflammatory cytokines, and a decrease in the hyperactivity of immunological markers.

3. The therapeutic effect of «Respibron» (bacterial lysate of 13 strains of microorganisms) can be assessed as expressive and more powerful in comparison with «Imudon».

The obtained results make it possible to continue the study of the course of experimental periodontitis from the point of view of establishing the mechanisms of development, protection, and restoration of tissues under conditions of pharmacological correction with bacterial lysate «Respibron».
\end{abstract}

Keywords: periodontitis, cytokine imbalance, bacterial lysate, immune response.

DOI: $10.21303 / 2504-5679.2021 .001970$ 


\section{Introduction}

Generalized periodontitis occupies one of the leading places among the most common human diseases (WHO, 1990) and leads to tooth loss five times more often than caries and its complications $[1,2]$. According to the latest latest epidemiological studies, the prevalence of dystrophic-inflammatory periodontal diseases in Ukraine among young people of working age ranges from 85 to $100 \%$, which determines the social significance of this problem [3]. In this regard, the treatment of periodontal diseases remains one of the urgent medical and social problems in modern dentistry.

The development and progression of periodontitis is based on the mechanisms of imbalance between microflora and protective factors, regulated by immune mechanisms. As a result, autoimmune reactions and inflammation are triggered, which leads to the destruction of the body's own structures. Pro-inflammatory (IL-1 $\beta$, IL-6, IL-8, TNF- $\alpha$ ) and anti-inflammatory (IL-4, IL-10) cytokines are involved in the regulation of inflammatory processes [4,5]. These substances belong to a group of regulatory peptides involved in all stages of the immune response. Cytokines exhibit universal biological effects to the action of various pathogenic factors. They are important regulators of inflammation, intercellular interactions at the local and systemic levels. There are activation of lymphocytosis, phagocytosis, synthesis of interferons, stimulation of mitosis, and there are many reactions, which responsible for other processes associated with the inflammatory response [6, 7].

It has been proven that the dystrophic-inflammatory process in the periodontal tissues develops both against the background of decreased immune responses of nonspecific and specific local immunity, in particular in the oral cavity, and against the background of insufficient immune protection at the level of the whole organism [8]. Therefore, one of the leading places in the treatment of periodontal disease is immunocorrective therapy [9].

According to the literature, the chronic inflammatory process is caused by the damaging effect of the pathogen on the mucous membrane and the development of immunodeficiency due to the activation of free radical oxidation and an imbalance of pro-inflammatory and anti-inflammatory cytokines. This leads to cell apoptosis and cell alteration of various origins [10].

In connection with the above, the next stage of our work was to study the role of imbalance in the cytokine system in experimental periodontitis, which regulate intercellular interactions of all links of the immune system and intersystem interactions and the influence of «Respibron» on immune status experimental periodontitis.

The aim of this article was the correction of a disturbed cytokine profile by a bacterial lysate in an experimental model of periodontitis against the background of changes in the local and systemic immune response on the basis of the Central Research Laboratory of the NUPh. The scientific novelty based on pathophysiological research of the peculiarities of the course of the disturbed cytokine profile on an experimental model of periodontitis and its pharmacological correction. The work was carried out in accordance with the research plan of the National University of Pharmacy («Technology of obtaining original and combined drugs in various forms», research work No. 0108U009174). The practical significance of carrying out a number of pathophysiological studies for medical practice lies in the theoretical generalization and new solution of the urgent scientific and practical problem of modern biological and medical pathological physiology - the role of the influence of bacterial lysates in the pathogenetic therapy of periodontitis, which makes it possible to pathogenetically substantiate the principles of correction of this pathological process.

\section{Materials and methods}

The studies were carried out at the Central Scientific Research Laboratory of the NUPh, which is certified by the State Pharmacological Center of the Ministry of Health of Ukraine (certificate No. 008/11 dated 18.10.2011). Experiments were carried out in the fall of 2020 on 48 outbred male rats weighing 180-190 g. Experimental periodontitis in rats was caused by keeping rats on a light consistency diet with a high carbohydrate content by O. I. Evdokimov modified by A. I. Sukmansky and A. Makarenko [11]. The animals were divided into 4 groups: $1^{\text {st }}$ group - intact animals; $2^{\text {nd }}$ group - rats with experimental periodontitis; $3^{\text {rd }}$ - rats with experimental periodontitis, which were irrigated with an aqueous solution of «Respibron» at a dose of $10 \mathrm{mg} / \mathrm{kg}$ once a day; $4^{\text {th }}$ group - rats with experimental periodontitis, which were irrigated with an aqueous solution of 
the reference drug. The duration of the experiment was 90 days: the simulation of periodontitis lasted 60 days (30 days were treated with «Respibron» (bacterial lysate) and the reference druga well-known agent with immunomodulatory properties «Imudon», which includes lysates of strains of the most common bacterial pathogens of the pathological process in the cavity mouth) [9]. Its mechanism of action is to stimulate the protective reactions of the oral mucosa by increasing the phagocytic activity of polymorphonuclear leukocytes (PML), the content of lysozyme in mixed saliva, stimulation of immunocompetent cells, as well as stimulation and increase of secretory $\operatorname{IgA}$.

Determination of the level of cytokines in the blood serum was carried out by the enzyme immunoassay [12] on the analyzer «Multiscane Biotech» using test systems manufactured by «Caltag laboratories» (USA). Obtaining blood serum for determining biochemical parameters: animals were decapitated under inhalation anesthesia, blood was collected in silicone tubes. Blood serum was obtained by conventional methods. The samples were incubated in a thermostat at $37^{\circ} \mathrm{C}$ for 20 minutes, centrifuged at $3000 \mathrm{rpm}$ for 15 minutes.

Circulating immune complexes: precipitation method with $3.5 \%$ polyethylene glycol solution PEG test OP280. A solution of polyethylene glycol (PEG) is capable of precipitating aggregated immune globulins and immune complexes from serum. The change in the density of the solution is recorded on a spectrophotometer at a wavelength of $250 \mathrm{~nm}$. Different concentrations of PEG $(2.5 ; 3.5 ; 7$ and even $10 \%$ ) cause precipitation of immune complexes of different molecular weights and sizes. Low concentrations of PEG precipitate large complexes, while high concentrations cause precipitation of low molecular weight compounds. $3.5 \%$ PEG flocculates the most common «intermediate» complexes of medium size. The level of circulating immune complexes (CIC) is measured on a spectrophotometer at $280 \mathrm{~nm}$ and is expressed in units of optical density [13].

C-reactive protein (CRP) was determined using a latex diagnosticum (CRP - latex test, NPL Granum LLC, Ukraine). The principle of the method is based on the detection in human blood serum of an acute phase protein - C-reactive protein, which enters into an agglutination reaction with antibodies against $\mathrm{C}$-reactive protein adsorbed on neutral latex particles. C-reactive protein was quantified [13].

Evaluation of the results of biochemical studies was carried out in accordance with existing standards by comparing the indicators of the comparison group with the main and initial indicators, as well as between the subgroups of the comparison group, depending on the exposure of the experiment [13].

All interventions and euthanasia of animals were carried out in compliance with the principles of the «European Convention for the Protection of Vertebrate Animals used for Experimental and Other Scientific Purposes» (Strasbourg, 1986, as amended in 1998) and the resolution of the Fifth National Congress on Bioethics (Kyiv, 2013).

The NUPh Bioethics Commission did not find any violations of moral and ethical standards during research work (protocol No. 1 dated 02/05/2020).

The animals were taken out of the experiment by decapitation under light inhalation anesthesia (desiccator).

Statistical analysis of the data was carried out to determine the arithmetic mean (X) and its statistical error (Sx) for groups with a normal distribution of characteristics, and the median (Me) and minimum and maximum dates for groups with an abnormal distribution of characteristics. To analyze the differences, the Newman-Keisley test and the Dunnett test were used. Evaluation of «0» hypotheses was carried out at a significance level of no more than 0.05 [13].

\section{Research results}

On the 60th day of the experiment, the concentration of IL-1 $\beta$ was 1.5 times higher than the value in the intact control group, and tumor necrotic factor (TNF- $\alpha)-2.6$ times. However, the content of anti-inflammatory IL-10 remained almost at the level of intact control (Table 1). Thus, the concentration of pro-inflammatory cytokines significantly increases in experimental periodontitis.

On the 90th day of the experiment, the concentration of IL-1 $\beta$ increased 1.7 times, and TNF- $\alpha-3$ times. Along with this, the concentration of the anti-inflammatory cytokine IL-10 significantly decreased by 1.6 times. 
Table 1

The influence of «Respibron» on the dynamics of the level of cytokines in the blood of rats with experimental periodontitis in comparison with «Imudon», $(\mathrm{M} \pm \mathrm{m} ; n=8)$

\begin{tabular}{|c|c|c|c|}
\hline Animal groups & IL-1ß, pg/ml & TNF- $\alpha, p g / m l$ & IL-10, pg/ml \\
\hline \multicolumn{4}{|c|}{60 days of experiment } \\
\hline Intact control & $37.53 \pm 1.68$ & $42.56 \pm 3.50$ & $49.67 \pm 3.55$ \\
\hline Control pathology (periodontitis) & $58.38 \pm 6.36^{*}$ & $105.15 \pm 6.8^{*}$ & $38.00 \pm 3.58$ \\
\hline «Respibron»+ periodontitis & $55.56 \pm 3.58^{*}$ & $128.99 \pm 9.42 *$ & $39.75 \pm 2.61$ \\
\hline «Imudon»+ periodontitis & $57.25 \pm 4.32 *$ & $133.93 \pm 8.39 *$ & $37.32 \pm 3.84$ \\
\hline \multicolumn{4}{|c|}{90 days of experiment } \\
\hline Intact control & $38.59 \pm 2.61$ & $44.33 \pm 4.17$ & $47.01 \pm 2.78$ \\
\hline Control pathology (periodontitis) & $64.56 \pm 1.71^{*}$ & $138.30 \pm 13.84^{*}$ & $28.72 \pm 2.13^{*}$ \\
\hline «Respibron» + periodontitis & $42.48 \pm 1.97 * *$ & $64.27 \pm 9.39 * *$ & $45.75 \pm 4.54 * *$ \\
\hline «Imudon»+ periodontitis & $48.06 \pm 2.46^{* *}$ & $77.66 \pm 8.58 * / * *$ & $41.58 \pm 2.55$ \\
\hline
\end{tabular}

Note: * the differences are statistically significant to the indices of intact control, $p<0.05 ; * *$ - the differences are statistically significant to the indicators of control pathology, $p<0.05$; \#-differences are statistically significant to the indicators of the «Imudon» group, $p<0.05 ; n$ - the number of animals in the group

Interleukin $1 \beta$ (IL-1 $\beta)$ is a key pleiotropic pro-inflammatory cytokine that plays a fundamental role in the development of inflammation [3, 4]. Its functions are to initiate and regulate inflammatory processes, stimulate the synthesis of acute phase proteins and other cytokines (IL-2, IL-3, IL-6, TNF). IL-1 is able to produce by some cells tumor necrosis factor- $\alpha$ (TNF- $\alpha)[6,14]$. Thus, the presented results indicate that dysregulation of the production of various forms of cytokines is observed in animals with experimental periodontitis.

Applying of «Respibron» for experimental periodontitis in rats, the concentration of IL-1 $\beta$ and TNF- $\alpha$ statistically significantly decreased in comparison with the indicators of animals from the control pathology group by 1.5 and 2.2 times, respectively $(p<0.05)$ and was equal to intact control (Table 1).

Against the background of the comparison «Imudon», a restoration of the balance of pro-inflammatory and anti-inflammatory cytokines was also observed, but to a lesser extent than with the use of «Respibron». Thus, the content of IL-1 $\beta$ decreased to the level of intact animals, however, the concentration of TNF- $\alpha$ and IL-10, although it decreased in the control pathology, did not reach the values of the physiological norm (Table 1). All of these changes were statistically significant.

Interleukin 10 (IL-10) is one of the main anti-inflammatory cytokines. Like IL-1 $\beta$, it exhibits multiple pleiotropic effects in the regulation of immune processes and inflammation. As our studies have shown, the content of IL-10 in chronic periodontitis in the blood of animals with control pathology increases 1.8 times compared with intact values. Applying of «Respibron» for experimental periodontitis in rats, the concentration of IL-10 statistically significantly decreased in comparison with the indicators of animals from the control pathology group and was equal to intact control.

As our studies have shown, the content of CIC in chronic periodontitis in the blood of animals with control pathology increases 1.8 times compared with intact values. At day 90 of the experiment, the concentration of CIC in the blood of rats from the control pathology group exceeded the value of intact animals by 2 times (Table 2).

In our experiment, the level of C-reactive protein increased 7.2 times at 60 days, and remained elevated 4.4 times at 90 days of observation compared with intact animals. Some reduction of this indicator on 90 days of experience testifies to spontaneous convalescence of inflammatory process at rats from group of control pathology.

When using «Respibron», the CIC content decreased to the level of intact values. A significant decrease in the content of CRP was also observed, however, a complete normalization of this indicator did not occur with the use of the test agent (Table 2). 
Table 2

The effect of «Respibron» on the dynamics of CIC and CRP in the serum of rats with experimental periodontitis in comparison with «Imudon» $(\mathrm{M} \pm \mathrm{m} ; n=8)$

\begin{tabular}{|c|c|c|}
\hline Animal groups & CIC, $3.5 \%$ & CRP, g/l \\
\hline \multicolumn{3}{|c|}{60 days of experiment } \\
\hline Intact control & $0.17 \pm 0.01$ & $5(4 ; 6)$ \\
\hline Control pathology (periodontitis) & $0.31 \pm 0.03$ & $36(24 ; 48)^{*}$ \\
\hline$«$ Respibron» + periodontitis & $0.30 \pm 0.02$ & $36(24 ; 42)^{*}$ \\
\hline «Imudon»+ periodontitis & $0.31 \pm 0.03$ & $30(24 ; 48)^{*}$ \\
\hline \multicolumn{3}{|c|}{90 days of experiment } \\
\hline Intact control & $0.18 \pm 0.01$ & $5.5(4 ; 6)$ \\
\hline Control pathology (periodontitis) & $0.38 \pm 0.02 *$ & $24(24 ; 36)^{*}$ \\
\hline «Respibron» + periodontitis & $0.23 \pm 0.03^{* *}$ & $6(10 ; 12)^{* / * *}$ \\
\hline «Imudon»+ periodontitis & $0.28 \pm 0.03 * / * *$ & $12(12 ; 24)^{* / * *}$ \\
\hline
\end{tabular}

Note: * - the differences are statistically significant to the indices of intact control, $p<0.05 ; * *$ - the differences are statistically significant to the indicators of control pathology, $p<0.05$; \#-differences are statistically significant to the indicators of the «Imudon» group, $p<0.05 ; n$-the number of animals in the group

The dynamics of the CIC and CRP against the background of the use of the reference drug «Imudon» was similar to that observed with the introduction of «Respibron», but to a somewhat lesser extent - the concentrations of both CIC and CRP decreased relative to the values in the control pathology group, but remained elevated relative to the values in the intact control group (Table 2). These changes were statistically significant.

\section{Discussion}

In recent decades, a number of studies have been published that characterize the development of experimental periodontitis from the viewpoint of immunological disorders [15]. Deserves special attention the idea of $[6,16]$ bacterial contamination as a factor of the development of experimental periodontitis, which was proposed in 2015 [14]. There is proposed the concept of an increase in the role of bacterial contamination in patients with periodontitis against the background of a decrease in the expression of antimicrobial peptides in the epithelium of oral cavity, which can further lead to invasion of initiation of chronic systemic inflammation [17, 18]. Our study of the spectrum of cytokines showed that the concentration of pro-inflammatory cytokines significantly increases at the 60th and 90th day of the experiment (concentration of IL-1 $\beta$ and TNF- $\alpha$ and anti-inflammatory IL-10 significantly decreased. The obtained dynamics of changes in the studied cytokines correlates with the data of other researchers and indicates the development of an imbalance in the ratio of pro-inflammatory/anti-inflammatory cytokines in experimental periodontitis [19].

Interleukin $1 \beta$ (IL-1 $\beta)$ is a key pleiotropic pro-inflammatory cytokine that plays a fundamental role in the development of inflammation [20]. Its functions are to initiate and regulate inflammatory processes, activate neutrophils, T- and B-lymphocytes, stimulate the synthesis of acute phase proteins and other cytokines (IL-2, IL-3, IL-6, TNF). It is IL-1 $\beta$ that induces the synthesis of low molecular weight mediators of inflammation (nitric oxide and prostaglandins), chemokines that attract neutrophils to the inflammation zone, trigger the expression of adhesion molecules on leukocytes and endothelial cells [21].

It has been shown that IL-1 $\beta$ is of the greatest importance in the development of the primary immune response to infection with periodontal pathogenic microbiota - in this pathology, its concentration in the gingival and oral fluids increases already in the early stages of inflammation. Borzikova N. S. (2015) proved that the concentration of IL-1 $\beta$ in the oral fluid has a positive correlation with the depth of the periodontal pocket. Interleukin-1 $\beta$ promotes the generalization of the inflammatory process in the periodontium $[6,14]$. 
IL-1 is able to enhance its production by some cells, which contributes to the rapid growth of its level. It has been shown that in response to not only a microbial agent, but also under the influence of other cytokines, many non-immune cells (keratinocytes, fibroblasts) can also increase the production of IL-1 $\beta$ and tumor necrosis factor- $\alpha$ (TNF- $\alpha)$ [8]. At the earliest stages of the development of inflammation, IL-1 and TNF- $\alpha$ stimulate the migration of leukocytes to the inflammation focus. Their secondary effect is manifested as a result of the induction of the synthesis of pro-inflammatory cytokines - for example, IL-6, which potentiates the inflammatory response [20].

It has been shown that in periodontitis, one of the cytokine-dependent mechanisms of the destruction of the extracellular matrix is the overproduction of TNF- $\alpha$, which is induced by microbial agents due to the activation of matrix metalloproteases [22]. All of these cytokines activate the synthesis of eicosanoids, matrix metalloproteinases (MMPs), and reactive oxygen species in tissues [5]. The immune response to infection leads to destruction of the tissues of the oral cavity and, as a result, to the systemic distribution of lipopolysaccharides (LPS), which in patients with hyperreactivity maintains the inflammatory response for a long time. In this case, systemically activated immune cells are attracted to the focus of inflammation. In the works [4, 20], a correlation was established between the level of pro-inflammatory cytokines in the gingival fluid with the concentration of microbial LPS in the blood plasma and clinical manifestations of periodontitis.

Thus, the presented results indicate that dysregulation of the production of various forms of cytokines is observed in animals with experimental periodontitis. An imbalance in the ratio of pro-inflammatory and anti-inflammatory factors determines the destructive nature of inflammation and its severity.

Applying of «Respibron» for experimental periodontitis in rats, the concentration of IL-1 $\beta$ and TNF- $\alpha$ statistically significantly decreased in comparison with the indicators of animals from the control pathology group. Against the background of the comparison «Imudon», a restoration of the balance of pro-inflammatory and anti-inflammatory cytokines was also observed, but to a lesser extent than with the use of «Respibron».

Interleukin 10 (IL-10) is one of the main anti-inflammatory cytokines. Like IL-1 $\beta$, it exhibits multiple pleiotropic effects in the regulation of immune processes and inflammation. Under the influence of IL-10, the expression of cytokines, T-helper-1 lymphocytes (Th1), MHC class II antigens and co-stimulating molecules on macrophages decreases, the induction of the secretion of inflammatory cytokines TNF- $\alpha$ and IL-1 $\beta$ is suppressed, the production of antibodies is activated [14].

An imbalance of pro / anti-inflammatory cytokines in the blood of animals from the group of control pathology towards an increase in proinflammatory pathology indicates the development of not only local inflammation, but also the generalization of the inflammatory process, which is confirmed by the formation of an average mass Circulating Immune Complexes (CIC) - markers of the development of autoimmune processes in response to the formation of toxic products of endothelial decay and periodontal tissues [6].

As our studies have shown, the content of CEC in chronic periodontitis in the blood of animals with control pathology increases much more compared with intact values. Normally, CECs are removed from the body by cellular, biochemical and enzymatic mechanisms by a system of mononuclear and tissue phagocytes, which are activated in the classical way by the complement system. Under normal conditions, excess CEC is effectively removed by phagocytosis, resulting in high concentrations of CEC do not lead to their pathologically significant accumulation. However, when the phagocytic activity of macrophages decreases, CECs are difficult to eliminate from the body [7]. One of the significant factors important for the manifestation of CEC pathogenicity is their size. The greatest pathological effects are exerted by CECs of medium size, formed with a small excess of antigen, capable of activating complement in an alternative way, which helps to maintain the inflammatory process [18]. At day 90 of our experiment, the concentration of CIC in the blood of rats from the control pathology group exceeded the value of intact animals.

C-reactive protein (CRP) is found in serum in various inflammatory and necrotic processes and reflects the intensity of the inflammatory process. By binding to $\mathrm{T}$ lymphocytes, it affects their functional activity, initiating reactions of precipitation, agglutination, phagocytosis and 
complement fixation. In our experiment, the level of C-reactive protein increased in 4.4 times at 90 days of observation compared with intact animals. Some reduction of this indicator on 90 days of experience testifies to spontaneous convalescence of inflammatory process at rats from group of control pathology. Applying of «Respibron», the CIC content decreased to the level of intact values. The dynamics of the CIC and CRP against the background of the use of the reference drug «Imudon» was similar to that observed with the introduction of «Respibron», but to a somewhat lesser extent - the concentrations of both CIC and CRP decreased relative to the values in the control pathology group, but remained elevated relative to the values in the intact control group.

Study limitations. The study of deep relationships of microbial associations, local immune mechanisms, analysis of the potential effects of anti-inflammatory therapy with bacterial lysates can be obtained in an experiment on animals, which is possible in future studies.

A prospective study of the cytokine mechanisms of the course of chronic periodontitis of the oral cavity against the background of changes in the parameters of immune relationships will make it possible to find ways of rational therapeutic tactics on the example of the action of the natural microbiota of preparations of bacterial lysates. This will allow analysis of the potential effects of such anti-inflammatory therapy in future studies.

\section{Conclusion}

1. It has been proved that by the end of the 90-day period of observation of the course of experimental periodontitis, the power of natural compensatory mechanisms acquired a state of decompensation. It has manifested by increased pro-inflammatory cytokine IL-1 $\beta$ in 1.7 times, and TNF- $\alpha$ in 3 times, decreased anti-inflammatory cytokine IL-10 in 1.6 times; increased the concentration of CIC in the blood in 2 times, C-reactive protein in 4.4 times at the local level in the gum tissue homogenate of the control pathology group of animals.

2. The powerful corrective effect of bacterial lysates «Respibron» and «Imudon» on the indicators of the cytokine series on the model of chronic experimental periodontitis has been reliably established. The normalizing effect is due to the compensation of bacterial dysbiosis, restoration of the balance of the activity of pro- and anti-inflammatory cytokines, and a decrease in the hyperactivity of immunological markers.

3. The therapeutic effect of «Respibron» (bacterial lysate of 13 strains of microorganisms) can be assessed as expressive and more powerful in comparison with «Imudon».

The results obtained make it possible to continue the study of the course of experimental periodontitis from the point of view of establishing the mechanisms of development, protection, and restoration of tissues under conditions of pharmacological correction with bacterial lysate «Respibron».

\section{Conflict of interests}

The authors declare that they have no conflicts of interest.

\section{Financing}

The study was performed without financial support.

\section{Acknowledgments}

We express our gratitude to the senior researcher, candidate of biological sciences Laryanovskaya Yu. B.

\section{References}

[1] Borisenko, A. V. (2013). Zabolevaniya parodonta. Kyiv: VSI «Meditsina», 455.

[2] Miklyaev, S. V., Leonova, O. M., Suschenko, A. V. (2018). Analiz rasprostranennosti khronicheskikh vospalitelnykh zabolevaniy tkaney parodonta. Sovremennye problemy nauki i obrazovaniya, 2. Available at: https://www.science-education.ru/ $\mathrm{ru} /$ article/view? id $=27454$

[3] Dimitrova, A. G., Kolenko, Yu. G. (2013). Otsenka effektivnosti razlichnykh immunomodulyatorov v kompleksnom lechenii generalizovannogo parodontita u lits molodogo vozrasta (18-25 let). Sovremennaya stomatologiya, 2, 38-39. 
[4] Schett, G., Dayer, J.-M., Manger, B. (2015). Interleukin-1 function and role in rheumatic disease. Nature Reviews Rheumatology, 12 (1), 14-24. doi: http://doi.org/10.1038/nrrheum.2016.166

[5] Gabay, C., Lamacchia, C., Palmer, G. (2010). IL-1 pathways in inflammation and human diseases. Nature Reviews Rheumatology, 6 (4), 232-241. doi: http://doi.org/10.1038/nrrheum.2010.4

[6] Ramich, T., Asendorf, A., Nickles, K., Oremek, G. M., Schubert, R., Nibali, L. (2018). Inflammatory serum markers up to 5 years after comprehensive periodontal therapy of aggressive and chronic periodontitis. Clinical Oral Investigations, 22 (9), 3079-3089. doi: http://doi.org/10.1007/s00784-018-2398-x

[7] Corona, P. S., Lung, M., Rodriguez-Pardo, D., Pigrau, C., Soldado, F., Amat, C., Carrera, L. (2018). Acute periprosthetic joint infection due to Fusobacterium nucleatum in a non-immunocompromised patient. Failure using a Debridement, Antibiotics + Implant retention approach. Anaerobe, 49, 116-120. doi: http://doi.org/10.1016/j.anaerobe.2017.12.010

[8] Bose A, Shetty S, Ajila V. Molecular biology of host microbial interaction in periodontal disease. LAP LAMBERT Academic Publishing. 2013;160.

[9] Sidelnikova, L. F., Dimitrova, A. G., Kolenko, YU. G. (2013). Estimation of efficacy of usage of immunomodulator in complex treatment of generalized parodontitis. Stomatologiya: ot nauki do praktiki, 1, 86.

[10] Lutskaya, I. K. (2017). Bolezni parodonta. Moscow: Meditsinskaya literatura, 256.

[11] Butenko, H. M., Tereshina, O. P., Maksymov, Yu. M., Arkadiev, V. H et. al.; Stefanov, O. V. (Ed.) (2001). Vyvchennia imunotoksychnoi dii likarskykh zasobiv. Doklinichni doslidzhennia likarskykh zasobiv. Kyiv: Avitsena, 102-114.

[12] Sennikov, S. V., Silkov, A. N. (2005). Methods for cytokine detection. TSitokiny i vospalenie, 4 (1), 22-27.

[13] Kushkun, A. A. (2007). Rukovodstvo po laboratornym metodam diagnostiki. Moscow: «GEOTAR-Media», 800.

[14] Borzikova, N. S. (2015). Markers of inflammation in the periodontal diseases. Medical Council, 2, 78-79.

[15] Refulio, Z., Rocafuerte, M., de la Rosa, M., Mendoza, G., Chambrone, L. (2013). Association among stress, salivary cortisol levels, and chronic periodontitis. Journal of Periodontal \& Implant Science, 43 (2), 96-100. doi: http://doi.org/10.5051/ jpis.2013.43.2.96

[16] Pedigo, R. A., Amsterdam, J. T. (2018). Oral medicine. Rosen's emergency medicine: concepts and clinical practice. Philadelphia: Elsevier, 843-857. doi: http://doi.org/10.1016/b978-0-323-05472-0.00068-2

[17] Ortiz-García, Y. M., García-Iglesias, T., Morales-Velazquez, G., Lazalde-Ramos, B. P., Zúñiga-González, G. M., OrtizGarcía, R. G., Zamora-Perez, A. L. (2019). Macrophage Migration Inhibitory Factor Levels in Gingival Crevicular Fluid, Saliva, and Serum of Chronic Periodontitis Patients. BioMed Research International, 2019, 1-7. doi: http://doi.org/10.1155/2019/7850392

[18] Ushakov, R. V., Gerasimova, T. P. (2017). Mekhanizmy tkanevoy destruktsii pri parodontite. Stomatologiya, 4, 63-65.

[19] Dommisch, H., Kebschull, M.; Newman, M. G., Takei, H. H., Klokkevold, P. R., Carranza, F. A. (Eds.) (2015). Chronic periodontitis. Carranza's clinical periodontology. Chap. 23. St Louis: Elsevier Saunders, 313-320.

[20] Sunkavalli, A. (2012). The role of cytokines in periodontal diagnosis. LAP LAMBERT Academic Publishing, 97.

[21] Kavrikova, D., Borilova Linhartova, P., Lucanova, S., Poskerova, H., Fassmann, A., Izakovicova Holla, L. (2019). Chemokine Receptor 2 (CXCR2) Gene Variants and Their Association with Periodontal Bacteria in Patients with Chronic Periodontitis. Mediators of Inflammation, 2019, 1-8. doi: http://doi.org/10.1155/2019/2061868

[22] Ponomareva, N. A., Gus'kova, A. A., Mitina, E. N., Grishin, M. I. (2017). Modern methods of treatment of inflammatory diseases of the parodont. The Journal of Scientific Articles «Health and Education Millennium», 19 (10), $123-125$. doi: http://doi.org/10.26787/nydha-2226-7425-2017-19-10-123-125

How to cite: Evtushenko, M., Kosheva, E., Kryzhna, S. (2021). Study of influence of bacterial lysate on cytokine indicators in experimental periodontis in rats. EUREKA: Health Sciences, 4, 73-80. doi: http://doi.org/10.21303/2504-5679.2021.001970 